\title{
How Do Different Self-Presentation Strategies Affect Bridging and Bonding Social Capital on SSNs? An Empirical Study of the WeChat Users in China
}

\author{
Yang Pan ${ }^{1, a}$, Zhichao Cheng ${ }^{1, b}$, Yuan $\mathrm{Ni}^{2, \mathrm{c}}$ and Yiwen $\mathrm{Xu}{ }^{1, \mathrm{~d}}$ \\ ${ }^{1}$ School of Economics and Management, Beihang University, Beijing 100191, China; \\ ${ }^{2}$ School of Economics and Management, Beijing Information Science \& Technology University, \\ Beijing 100192, China. \\ a panyang0426@163.com, ${ }^{b}$ cheng97815@vip.163.com, ${ }^{c}$ niyuan230@163.com, \\ dlanyier0317@163.com
}

Keywords: Self-presentation strategies, social capital, WeChat users.

\begin{abstract}
The goal of this study is to examine the relationship between online self-presentation strategies and social capital (bonding and bridging) on social networking sites (SNSs). An online survey was conducted using a WeChat user sample (aged 18-22 years; 202 males, 216 females). The results showed that, the supplication strategy was positively associated only with online bonding social capital; exemplification and ingratiation strategies were positively associated with both two types of online social capital; however, no significant relationship was found between self-promotion strategy and online social capital. Theoretical implications and limitations are discussed.
\end{abstract}

\section{Introduction}

With the advances in wireless technology and the popularity of smart phones, SNSs further lower social communication obstacles by minimizing unfamiliarity and allowing users to interact with others anytime and anywhere. WeChat (WeiXin in Chinese), a widely used SNS, has become the one of the most important communication tools to establish and maintain social ties in China. Selfpresentation features are the most time-consuming activity in young people's use of SNS, such as via constructing a profile, updating their status, uploading photos, and posting comments. With regard to the role of self-presentation in social interaction, however, research to date has only examined the relation between the frequency of self-presentation behavior and online social capital. Little is known about the extent to which self-presentation strategies may be related to online social capital. Therefore, the aim of the present study is to ascertain if online self-presentation strategies are used to aid in the accumulation of social capital in an online context.

\section{Self-Presentation Strategies and Social Capital on WeChat}

Self-presentation is a process of consciously controlling the impressions that others form of them. Jones \& Pittman (1982) present a comprehensive taxonomy of self-presentation strategies [1], including: (1) ingratiation (using humorous statements to be liked by others); (2) intimidation (using threats to establish a powerful image); (3) self-promotion (publicizing individual abilities to be perceived as skilled and qualified); (4) exemplification (displaying ideological social norms to establish oneself as a moral model); and (5) supplication (presenting self as helpless to receive assistance from others). Jung, Youn, \& McClung (2007) examined the use of four of the selfpresentation strategies (excluding intimidation) in Korea Weblogs, and supported the viewpoint that individuals applied the same widely used self-presentation strategies offline as they did in online interaction [2].

Social capital refers to the sum of the actual or potential resources embedded within interpersonal relationships. Putnam (2002) suggested the social capital can be categorized in bridging and bonding social capital [3]. Bonding social capital focuses on emotionally close relationships and is related to 
"strong ties", whereas bridging social capital focuses on diversely heterogeneous relationships and is associated with "weak ties". Previous research has examined online self-presentation and selfdisclosure could help maintain offline acquaintance relationships and built new relationships with stranger on SNSs [4]. However, what type of online self-presentation strategies are related to social capital is remain unclear. Therefore, we put forward the following research question:

RQ: What is the relationship between certain type of self-presentation strategies and two types of social capital on WeChat?

\section{Method}

\subsection{Participants.}

A total of 418 WeChat users (aged 18-22; 51.7\% females and 48.3\% males) through a survey website (www.wjx.cn) completed an online survey. College students who had registered on this site and used WeChat for at least 3 months were randomly invited to participate in this survey.

\subsection{Measures.}

Online social capital. We used Williams' (2006) 20-item, 5-point ( 1 =strongly disagree; 5=strongly agree) scale to measure participants' perceptions of their bonding and bridging social capitals on WeChat [5].

Online self-presentation strategies. Items from the Interpersonal communication strategies scale of Jung, Youn \& Mcclung (2007) were used to assess online self-presentation strategies and we further modified them to suit for WeChat context. All the items were rated on a 5-point Likert scale ranging from "strongly disagree" to "strongly agree".

Control variables. These consist of the number of WeChat friends, the amount of time spent on WeChat per day, and the number of updates their WeChat status.

\section{Results}

Table 1 displays descriptive statistics of self-presentation strategies and online social capital and bivariate correlations with them. The data in parentheses represent the Cronbach $\alpha$ of each subscale.

Table 1. Means, standard deviations and correlations among the major variables

\begin{tabular}{ccccccccc}
\hline Variables & $\mathrm{M}$ & $\mathrm{SD}$ & 1 & 2 & 3 & 4 & 5 & 6 \\
\hline 1.SEL & 3.12 & 1.08 & $(0.82)$ & & & & & \\
2.SUP & 3.37 & 0.91 & 0.03 & $(0.72)$ & & & & \\
3.EXE & 3.63 & 0.79 & $0.33^{* *}$ & $0.17^{*}$ & $(0.66)$ & &. & \\
4.ING & 4.00 & 0.71 & $0.24^{* *}$ & $0.24^{* *}$ & $0.48^{* *}$ & $(0.68)$ & & \\
5.BRI & 3.88 & 0.61 & 0.11 & 0.08 & $0.42^{* *}$ & $0.35^{* *}$ & $(0.83)$ & \\
6.BON & 3.77 & 0.64 & 0.07 & $0.26^{* *}$ & $0.31^{* *}$ & $0.35^{* *}$ & $0.62^{* * *}$ & $(0.79)$ \\
\hline
\end{tabular}

Note: SEL=Self-promotion; SUP=Supplication; $\mathrm{EXE}=$ Exemplification; $\mathrm{ING}=$ Ingratiation; BRI=Bridging social capital; BON=Bonding social capital. $(* p<0.05, * * p<0.01, * * * p<0.001)$

The results of hierarchical multiple regression analyses are presented in Table 2 . The control variables (gender and WeChat usage) were entered as the first block of predictors, and the four selfpresentation strategies were added as the second block. Supplication, exemplification, and ingratiation strategies were found to have a significant, positively effect on online bonding social capital indicating these strategies are important predictors of bonding social capital. On the other hand, exemplification, and ingratiation strategies were found to consistently related to bridging social capital, which implied exemplification and ingratiation strategy could improve bridging social capital among emerging adults. 
Table 2. Regression social capital on online self-presentation strategies

\begin{tabular}{|c|c|c|c|c|c|c|c|c|}
\hline & \multicolumn{3}{|c|}{ Bonding social capital } & \multirow[b]{2}{*}{$\Delta \mathrm{R} 2$} & \multirow[b]{2}{*}{$\mathrm{B}(\mathrm{SE})$} & \multicolumn{3}{|c|}{ Bridging social capital } \\
\hline & $\mathrm{B}(\mathrm{SE})$ & $\beta$ & $\mathrm{R} 2$ & & & $\beta$ & $\mathrm{R} 2$ & $\Delta \mathrm{R} 2$ \\
\hline $\begin{array}{c}\text { Variables/ste } \\
\text { Step1 }\end{array}$ & & & & & & & & \\
\hline Gender & 0.06 & $-0.19 * * *$ & & & 0.06 & -0.04 & & \\
\hline WUF & 0.04 & $0.16^{* *}$ & & & 0.04 & $0.15 * *$ & & \\
\hline WUT & 0.03 & 0.08 & & & 0.03 & 0.04 & & \\
\hline WEF & 0.02 & $0.14^{*}$ & & & 0.02 & $0.19 * *$ & & \\
\hline $\begin{array}{c}\mathrm{F}(4,413) \\
\text { Step2 }\end{array}$ & & & 0.14 & $0.14 * * *$ & & & 0.10 & $0.10 * * *$ \\
\hline SEL & 0.03 & -0.04 & & & 0.03 & -0.04 & & \\
\hline SUP & 0.03 & $0.19 * * *$ & & & 0.03 & -0.01 & & \\
\hline EXE & 0.04 & $0.14 * *$ & & & 0.04 & $0.33 * * *$ & & \\
\hline ING & 0.05 & $0.16^{* *}$ & & & 0.04 & $0.16^{* *}$ & & \\
\hline $\mathrm{F}(3,366)$ & & & 0.26 & $0.12 * * *$ & & & 0.26 & $0.16^{* *}$ \\
\hline
\end{tabular}

Note: Gender was coded as 0 for female and 1 for male; WUF $=$ WeChat updating frequency; $\mathrm{WUT}=\mathrm{WeChat}$ use time; $\mathrm{WEF}=\mathrm{WeChat}$ friends; SEL=Self-promotion; SUP=Supplication; EXE=Exemplification; ING= Ingratiation.

$(* \mathrm{p}<0.05, * * \mathrm{p}<0.01, * * * \mathrm{p}<0.001)$.

\section{Discussion}

The goal of our study was to explore the relationship between varying online self-presentation strategies and two types of social capital. Based on the results of multiple regression analysis, online bonding social capital was predicted by three self-presentation strategies: supplication, exemplification, and ingratiation. These results indicated that users with good sense of humor, displaying ideological social norms, and presenting self as helpless will help in constructing a favorable identity of users to maintain their offline close relationship. On the other hand, online bridging social capital was predicted by two self-presentation strategies: exemplification and ingratiation. Exemplification strategy predicted most heavily on online bridging social capital, suggesting that users who disclosure their self-disciplined traits will be more likely to initiate online relationships with new people.

However, the results of the present study did not show a significant positive effect of selfpromotion on online social capital. To some extent, online self-promotion may be regarded as a form of bragging or openly self-flaunting. Based on collectivist social norm and tradition deeply rooted in Confucianism, East Asians like Chinese are more likely to value a modest self-image while refraining from boastful self-presentation [6]. Thus, we suggest that self-promotion may be considered a less appropriate strategy and not conducive to improving online relationships among Chinese WeChat users.

This study was limited in several ways. This study used a student sample that certainly does not represent the all WeChat population. Moreover, potential limitation lies in the relatively few selfpresentation strategies. Future research should consider specific self-presentational strategies employed in the online context, such as humblebrag, and investigate salaried employees to comprehensively understand the relationship between self-presentation strategies and social capital on SNSs.

\section{Acknowledgements}

This study was supported by the Beijing Social Science Foundation (Grant No.16GLa007). Corresponding Author: Pan Yang. E-mail: panyang0426@163.com. 


\section{References}

[1]. Jones, E. E., \& Pittman, T. S. (1982). Toward a general theory of strategic self-presentation. In J. Suls (Ed.), Psychological perspectives on the self (Vol. 1, pp. 231-262). Hillsdale, NJ: Erlbaum.

[2]. Jung, T., Youn, H., \& McClung, S. (2007). Motivations and self-presentation strategies on Korean-based "Cyworld" weblog format personal homepages[J]. Cyberpsychology Behavior \& Social Networking, 10(1), 24.

[3]. Putnam, R.D. (2000). Bowling alone: The collapse and revival of American community. New York, NY: Simon \& Schuster.

[4]. Shu-Chuan Chu, Sejung Marina Choi. Social capital and self-presentation on social networking sites: a comparative study of Chinese and American young generations[J]. Chinese Journal of Communication, 2010, 3(4):402-420.

[5]. Williams, D. (2006) On and off the 'Net: Scales for social capital in an online era[J]. Journal of Computer-Mediated Communication. 11 (2). p. 593-628.

[6]. Heine, S. J., Takata, T., \& Lehman, D. R. (2000). Beyond self-presentation: evidence for selfcriticism among Japanese[J]. Personality \& Social Psychology Bulletin, 26(1), 71-78. 